\title{
Design of the Car Intelligent Horn
}

\author{
Zheng Zhu-an ${ }^{1, a^{*}}$, CHEN Xiaobo,Gu Suqing,Lv hongming \\ ${ }^{1}$ School of Automotive Engineering, Yancheng Institute of Technology, Yancheng Jiangsu \\ azhengza10@mails.jlu.edu.cn
}

Key words:Satellite navigation, Level 3 early warning ,Smart reminder

\begin{abstract}
This paper designs a intelligent car horn based on RFID(radio frequency identification and satellite navigation technology)。Horn gets automobile accurate geographic position information by satellite navigation chip and realize the communication between the cars by the RF module. When the other car's whistle is blowing, the horn can accept the signal covering the vehicle speed and location information. What's more, it can quickly and accurately calculate the distance between vehicles to provide timely warning distance by sunplus. After testing,the horn is stable、 reliable and adaptable, which can effectively prevent the closed windows that the driver did not hear the whistle sound caused by traffic accidents and improve traffic safety.
\end{abstract}

\section{Introduction}

At present, the frequent occurrence of traffic accidents at home and abroad, by the window completely closed or vehicles speeding to factors such as the noise is too big the pilot failed to timely attention around the horns of vehicles which leads to its failure to make an accurate judgment such as collision, collision caused serious traffic accidents in the total proportion quite a number of traffic accidents. This new intelligent directivity horn to the driver to press it launch vehicle speed, accurate location information of the wireless signal, the receiving comprised single-chip computer calculation, put forward the three-level warning, selectively alert drivers, make its make a timely and effective safety measures, reduce the accident rate.

\section{The overall design scheme}

This design includes microcontroller development board, nRF24L01 communication module, GPS satellite navigation module, sound and light alarm module, 12864 LCD liquid crystal display module and stabilized voltage supply module. System USES LM1575 voltage chip to convert car $12 \mathrm{v}$ power supply for $5 \mathrm{v}$ power supply, the STC89C52 microcontroller as the control center, according to the relevant information from the processing, provide 3 warning scheme, at the same time using nRF24L01 wireless rf transceiver module for data sending and receiving, use of u-blox G5 chip module to obtain the latitude and longitude coordinates, at the same time, using 12864 type LCD liquid crystal display module information real-time display the vehicles detection, and use the buzzer and LED to achieve sound and light alarm. The overall system frame as shown in figure 1.

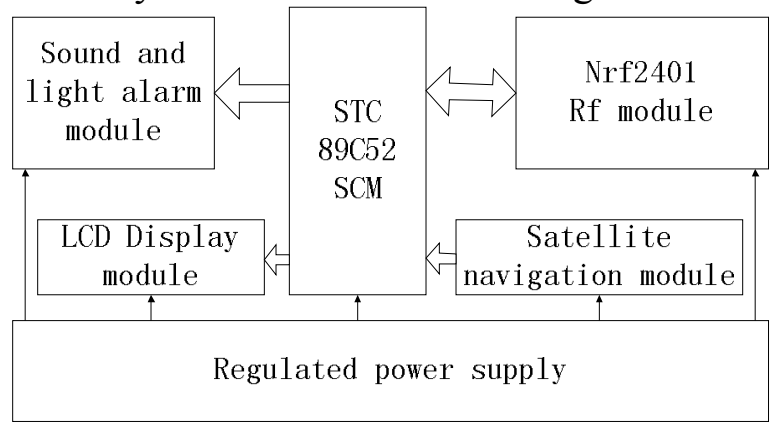

Fig. 1 The overall system frame 


\section{Hardware setup}

\section{single chip microcomputer}

STC89C52 on STC company is the production of a high performance, low power consumption CMOS8 microcontroller, with $8 \mathrm{k}$ in system programmable Flash memory. STC89C52 to use classical MCS-51 kernel, after doing much improved makes the chip has many traditional does not have the function of the 51 single-chip microcomputer. On a single chip, has the nimble 8-bit CPU and in system programmable Flash, make STC89C52 can provide very effective for many embedded control applications, high flexible solution.

\section{Wireless RF transceiver module}

NRF24L01 chip is a kind of universal ISM band single chip wireless transceiver chip, its work from 2.400 to $2.524 \mathrm{GHz}$, can also realize the function of multiple transmit and receive data.

This design USES the nRF2401 nRF2401 chip as the core module, a total of two sets of interface interface 1 were used respectively to send data; 2 receive data interface, so as to realize the two-way transmission of information.

\section{GPS satellite navigation module}

This horn satellite navigation module is adopted by the Beijing Oriental satellite navigation chip from the united star $\mathrm{u}$ - blox G5, can receive at the same time beidou no. 2, GPS, GLONASS satellite signal, realize the combination navigation and positioning system, time and speed.

\section{4 liquid crystal display module}

The speaker adopts 12864 formation LCD display module, it can display the surrounding, the car distance, default of latitude and longitude and related information. Some formation LCD display module can not only common character, also can display graphics and characters.

12864 LCD display module lateral 128 points, the longitudinal according to 64 points, can also show up to $16 \times 16$ Chinese characters 4 line 8 , can meet the demand of large amount of information display. Module pin connection as shown in figure 2.

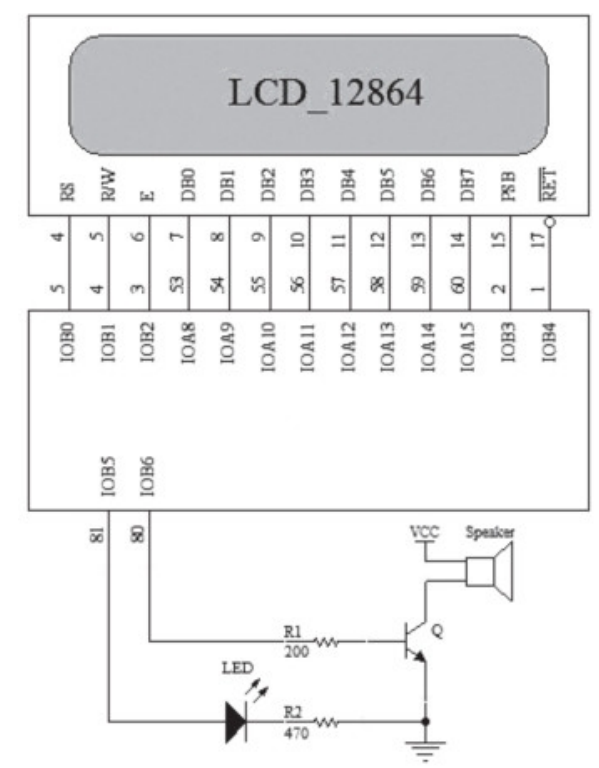

Fig.2 Module pin connection diagram

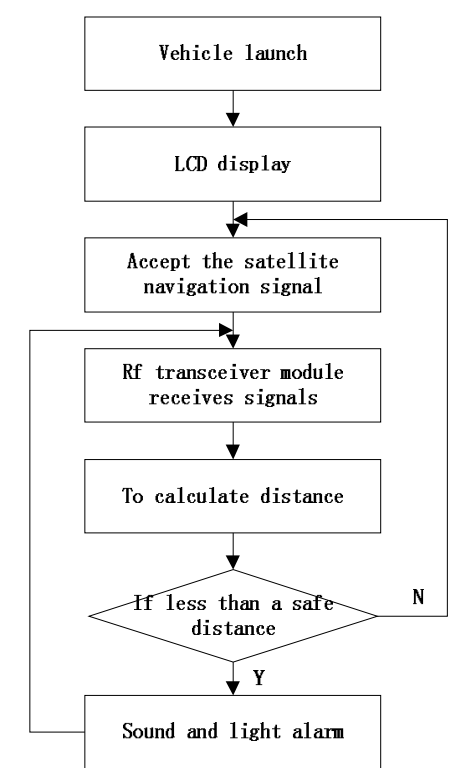

Fig.3 The flow chart of system software

\section{sound and light alarm circuit}

When the car is close to the distance, through the monolithic integrated circuit output signal, sound and light alarm work. This system USES LED and buzzer sound and light alarm, use two single chip microcomputer output port control system for the LED and buzzer, respectively. 


\section{Software Settings}

Vehicle starts up, the first horn self-inspection and initialization Settings. When he has other cars honking their horns, by radio frequency transceiver module receives its include vehicle identification from the serial number, once received the information such as velocity, latitude and longitude and its input to the MCU, MCU by controlling the rf transceiver module, the module nRF24L01 the channel 2 receive honking vehicle to send the information such as the latitude and longitude, latitude and longitude of the vehicle horns and will receive the information into the single chip microcomputer for processing.

Made by the latitude and longitude of the car through range velocity model to calculate the distance between the two cars, and two car distance comparing with safe distance, if the distance is less than the safe distance, the judgment before and after the relative moving direction and position of the vehicle, for synthetic and less than the safe distance, the single-chip microcomputer control LED lights flashing, control buzzer sound alarm at the same time. The system software flow chart is shown in figure 3.

\section{Auto ranging algorithm}

$\mathrm{Rf}$ transceiver module receives information mainly is the latitude and longitude information, etc., by the speaker on the real time information and default of latitude and longitude information for dynamic processing, can obtain the latest car every moment is apart from the information. First of all to the latitude and longitude information format definition. Define latitude north latitude for the positive $(+)$, south to the negative (-); Longitude information for "positive $(+)$ ", east longitude west longitude as "negative (-). The circumference of the earth is about $40008 \mathrm{~km}$, the average degree of latitude 1 is equal to about $111 \mathrm{~km}$. This horn to latitude and longitude information accuracy is 0.0001 , the one over ten thousand each units on behalf of the approximate distance equal to $11.1 \mathrm{~m}$, can meet the demand of precision horn. So, can get general ranging model:

$$
S=\sqrt{\left[\left(\mathrm{E}_{2}-\mathrm{E}_{1}\right) \mathrm{a}\right]^{2}\left[\left(\mathrm{~W}_{2}-\mathrm{W}_{1}\right) \mathrm{a}\right]^{2}}
$$

Formula 1, E1 and E2 respectively and other vehicles on the local longitude information, W1 and W2 respectively and other vehicles on the local information of latitude, a for $1^{\circ}$ latitude and longitude represent length, about $1.11 \times 105 \mathrm{~m}$. For special cases, such as in east longitude $180^{\circ}$ and west longitude $180^{\circ}$ boundary area, longitude conversion processing should be carried out before the operation. Default of the speed of computation, can be used the above range model of measured twice on the local longitude and latitude calculated longitude and latitude satellite navigation chip scan period $\mathrm{T}$ inside the vehicle movement distance, thus it is concluded that the speed $\mathrm{v}$.

\section{Horn performance testing}

Horn the focus of the performance test is to examine the rationality of the loudspeaker design and verify the functionality and reliability. Test for this horn, mainly from the horn of combining software and hardware test this aspect.

LM1575 module test. LM1575 module power output to the oscilloscope, observed after the power supply voltage fluctuation range in the range of horn requirement, can satisfy the requirements. To 12864 LCD liquid crystal display module and GPS satellite navigation module test, 12864 LCD can achieve the Chinese characters, characters and, according to the specific image of the liquid crystal display module test and correct. Satellite navigation program written to SCM, connection module, it receives the data displayed on the LCD display, shows the result is stable, as shown in figure 4. Radio frequency transceiver module testing. Connecting MCU, with two groups of tested transceiver module, all can correct to send and receive information. Sound and light alarm module testing. This module has good electrical connection. Will detect acousto-optic alarm program written to SCM, the module can be normal send out sound and light alarm signal. 


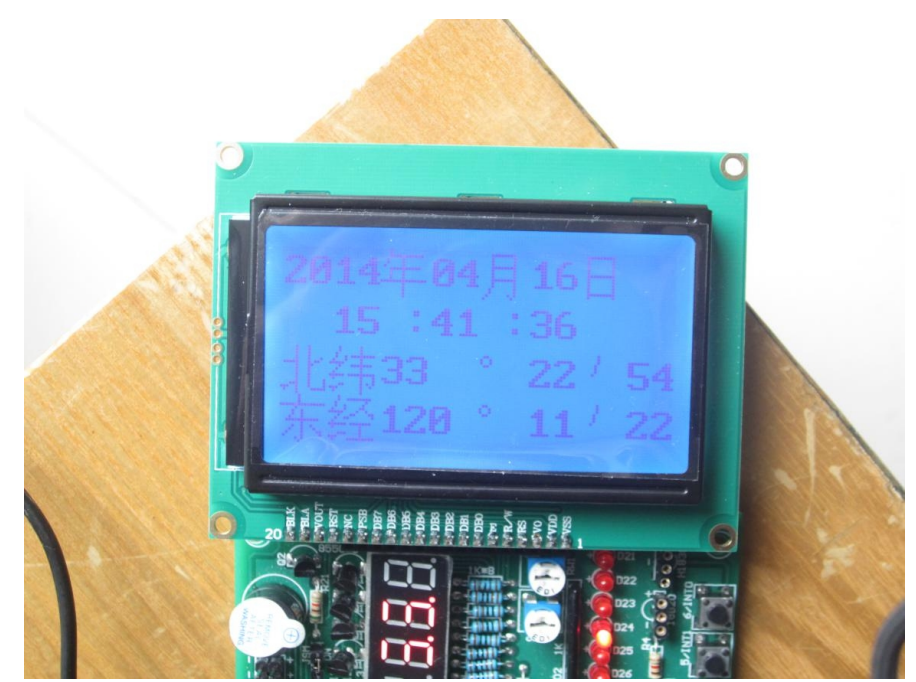

Fig.4 Liquid crystal display module test pattern

\section{Conclusions}

This new intelligent car directivity horn, through debugging, horn normal operation, to reach the expected aim. MCU level 3 early warning plan is also very perfect. But there are some places need to be further research, such as how to improve the accuracy of the GPS satellite navigation module and RFID more long distance communication, etc. Due to the limited conditions, only to do the test in the laboratory, and there is no actual installation to the vehicle test. So this new intelligent car directivity horn in anti-interference, stable performance, etc also need further discussion and research.

\section{References}

[1] RALLAPORAL S, QIU L, ZHANG Y, et al. Exploiting temporal stability and low-rank structure for localization in mobile networks [C] / / MobiCom'10: Proceedings of the Sixteenth Annual International Conference on Mobile Computing and Networking. New York: ACM, 2010: 167 172.

[2] YANG YANG, LI XU, SHU WEI, et al. Quality evaluation of vehicle navigation with CPS [C] / / IEEE Global Communications Conference Exhibition \& Industry Forum. [S. 1. ]: IEEE, 2010: $1-5$.

[3]ZHU HONG-ZI, ZHU YAN-MIN, LI MING-LU, et al. ANTS: Efficient vehicle locating based on ant search in ShanghaiGrid [J] . IEEE Transactions on Vehicular Technology, 2007, $58(8)$ : $4088-4097$.

[4] GE YONG, XIONG HUI, TUZHILIN A, et al. An energy-efficient mobile recommender system [C] // KDD'10: Proceedings of the 16th ACM SIGKDD International Conference on Knowledge Discovery and Data Mining. New York: ACM, 2010: 899 - 908.

[5] LIN HUI-JIA, LU MAO-HUA, MILOSAVLJEVIC N, et al. Composable information gradients in wireless sensor networks [C ] / IPSN'08: Proceedings of the 7th International Conference on Information Processing in Sensor Networks. Washington, DC: IEEE Computer Society, 2008: $121-132$.

[6] LIU Xiao-yang,WU Min-you. Vehicular CPS: an application of IoT in vehicular networks[J]. Journal of Computer Applications, 2012，32(4) : $900-904$ 